\title{
EDITORIAL
}

\section{Quality program in radiology: Persue or perish}

\section{Chander Mohan, SM}

Department of Interventional Radiology, BLK Superspecialty Hospital, New Delhi, India.

E-mail: brigcmohan@gmail.com

Medical imaging has seen tremendous growth in the past three and half decades with the introduction of various imaging modalities. The continuing growth of technological advances is leading to the introduction of newer clinical applications at a rapid pace. These advances are resulting in precise diagnosis and definitive treatment and have made the specialty of radiology integral to the practice of medicine. However, these technological advances have come at a price as radiological equipment is very costly and radiological investigations form a substantial part of the overall expenditure on treatment. This is seen as a lucrative business opportunity and has led to a mushrooming of imaging centers and taking over of radiology services of hospitals across the country even by nonradiologists and investors. Because the issue of excessive exposure to radiation can lead to detrimental effects for patients, it is important to ensure that patients are not subjected to unnecessary radiations. This can be achieved by a rational approach to investigations with proper indications and well-supervised studies eliminating the need to re-investigate because of poor quality. These objectives can be achieved by instituting a quality assurance program in providing cost-effective, prompt, and accurate diagnosis.

The aim of radiology departments should be to establish and maintain safety and quality of service, and try to continuously improve performance to practice, safe, accurate, and cost-effective radiological services. For actively achieving these objectives, quality management and regular monitoring of the highest order is required. This involves support from top management, quality department, radiologists, and staff involved in the quality improvement process.

The key areas of quality include:

- Proper infrastructure and physical facilities for equipment installations complaint with AERB guidelines, especially in the case of installation of refurbished equipment, regular servicing and periodic maintenance, periodic quality control checks of equipment, maintenance of such records of maintenance and checks, radiation warning signage to facilitate patient movements and warn patients of potential hazards, and duly approved signage required in two languages under the PC and
PNDT Act in ultrasound. Provision of changing rooms and unauthorized intrusion into the examination room should be ensured to respect the privacy of patients

- Radiation safety measures - The service must have provision of TLD badge and monitoring, lead aprons and thyroid shields, proper storage, and periodic testing of these protective hardware and their timely replacement. Availability of a radiation safety officer must be mandatory for all radiology set ups

- Availability of qualified and trained technical staff including radiologists to supervise studies and following of the ALARA principle must be ensured. The supervising radiologists must ensure proper indication, selection of optimal study with adherence to the ALARA principle, documentation of radiation doses in patient records for each imaging examination, and the implementation of dose reduction strategies. This is particularly important in oncology patients in requirement of follow up studies

- Tele-radiology - It is a powerful tool to ensure good quality of reporting in centers with a lack of availability of trained radiologists, either for modality or for second level reporting. However, it has issues of unsupervised and suboptimal imaging by technicians being sent to remote radiologists to provide service. Attention should be paid to the type of equipment, its limitations, hiring of trained skill personnel, and supervision by skilled radiologist to ensure optimal imaging

This is an open access article distributed under the terms of the Creative Commons Attribution-NonCommercial-ShareAlike 3.0 License, which allows others to remix, tweak, and build upon the work non-commercially, as long as the author is credited and the new creations are licensed under the identical terms.

\begin{tabular}{|l|l|}
\hline \multicolumn{2}{|c|}{ Access this article online } \\
\hline Quick Response Code: & Website: \\
\hline & www.ijri.org \\
\hline
\end{tabular}

Cite this article as: Mohan C. Quality program in radiology: Persue or perish. Indian J Radiol Imaging 2017;27:1-3. 
- Quality of reporting - The service must ensure timely and accurate reporting of imaging by competent staff with credentials. The adherence to reasonable turnaround time (TAT) for reporting various imaging studies with due emphasis on urgent reporting of critically sick and emergency cases to treating physicians. The use of abbreviations must be avoided as far as possible and the reports must be checked carefully for typographic errors, especially in the present era of typing on standard formats for various examinations by transcriptionists. The mechanism to seek second opinion for difficult/problem cases also must also be available. The feedback about final diagnosis must be obtained for each study to determine accuracy of reports

- Clinicoradiological and tumor board meetings must be held to discuss cases with concerned departments every week for discussing relevant imaging required based on clinical requirement and get feedback on final diagnosis

- Training and retraining to upgrade skills to be undertaken - The department needs to conduct regular training for all levels of staff for maintaining high level of professionalism and also encourage them to attend seminars, workshops, and conferences to upgrade their skills

- Radiation manuals and standard operating procedures (SOPs) must be read and signed at regular intervals by existing staff as well as new inductees. A designated radiation safety officer must be responsible for ensuring compliance of these requirements

- Safety measures - The service must have for SOP for patient safety starting from identification of right patient, site marking, handling of vulnerable patients such as provision of color coded wrist badges, use of restrainers and proper handling during shifting of critically sick patients with multiple tubes, and lines for imaging studies such as computed tomography scan and magnetic resonance imaging scan, noninvasive monitors, oxygen supply, and suction facilities. Moreover, the radiologists and technical staff should be trained in basic life support skills. It assumes particular significance in era of radiologists reporting from work stations in reporting rooms

- Handling of emergency situations - The service must have a SOP for handling various emergency situations such as collapse of patients during waiting period or during procedure, accidental falls during shifting, misplacement of lines and tubes, and fire accidents

- Open reporting policy of adverse events - The department must have an open policy to report adverse events, errors, and medical accidents without fear of punitive action. Staff should also be a part of deliberations and discussions to study the cause of such events and measures to prevent them in future

- Safety of staff - The imaging services must have adequate provision of personal radiation protective hardware such as lead aprons, thyroid and gonad shields with proper storage, regular scans for detection of cracks, documentation of such scans and timely replacement, and provision of TLD badges to staff working in radiation area.

Clear cut policy should be implemented for regular monitoring of radiation doses of staff, taking off the radiation work, the concerned staff in case of over exposure and pregnancy, and needle stick policy. The staff and doctors must be covered by adequate professional insurance to safeguard against litigations. The organization must have a policy of incentives and rewards to employees for compliance of policies and guidelines to encourage better participation

- Preprocedure work up - The case must be studied at time of scheduling for proper indication, type of examination/procedure required, coagulation assessment, history of bleeding disorders, ongoing anticoagulation medication, history of allergy, renal and cardiac assessment, need for antihypertensive and other essential medication and fasting status, and clear instructions must be given to make the procedure as safe as possible

- Informed consent - Proper briefing of all aspects of imaging and procedures, including the risks and benefits, must be done before obtaining informed consent. Unfortunately, this aspect is not given due attention, and nonobtaining of a proper informed consent may be considered as medical negligence in case of litigation. Adequate time should be spent on briefing the patient and attendants about all aspects of imaging examination, especially in case of procedures and all queries must be answered before obtaining informed consent. In case of language barrier, use of translators must be made and documented in the informed consent. Of course, in case of critically sick patients, surrogate informed consent needs to be obtained

- Communication with patients - The patients want to meet the radiologists and want to know the result of examination immediately after the imaging examination/procedure. The radiologist must make it a point to meet the patient and attendants and assure them that the result will be finalized after a thorough review of the images. It is advisable to be transparent to patients and attendants in case of adverse events and keep them informed. It leads to better customer satisfaction and may avoid litigation due to medical negligence

- Feedback from stake holders - Feedback from patients about the waiting period, preprocedure briefing, instructions after imaging/procedure, quality of service provided to assess satisfaction level/experience through surveys and text messages help in analyzing problem areas

- Disposing of biomedical waste - Proper segregation as per the appropriate color-coded dustbins and disposal of biomedical waste should be ensured as per existing laws 
- Spill policy - The staff should be aware of spill policy to deal with spillage of drainages of fluid, collections or abscesses, and must follow religiously

- Storage of controlled drugs - The drugs must be stored as per SOP and periodically checked for expiry/replenishment

- Intradepartmental meetings to discuss problem areas and find solutions - regular meetings must be held to discuss and review problem areas, adverse events and accidents, feedback from stake holders, and decisions taken must be communicated to all staff members

- Audit - A regular internal as well as external audit of radiology reports and procedures should performed by experts at least at every 3 months to get unbiased feedback.

Government has it made it mandatory for private hospital and imaging centers to get NABH accreditation for empanelment. Hence, the empaneled hospitals and imaging centers comply with above quality requirements to a large extent. However, despite huge workload, there is no documented quality assurance program (QAP) in most of the institutions, especially in the government set up, and these institutions are at best partially compliant in this aspect. Moreover, there are large number of nonaccredited hospitals and stand-alone imaging centers. There is wide variation in the infrastructure, equipment, availability of trained technical manpower, and lack of focus on quality parameters mentioned above. In fact, some centers do not have full-time qualified radiologists.

In the era where radiology is seen as money spinning specialty by nonradiologists and investors, Indian Radiological Imaging Association (IRIA) must take the lead, engage with government, and formulate guidelines to be followed by radiology set up at any level (irrespective of accreditation), where quality should form an essential requirement.

This will not only help to standardize the quality of radiology service to the patients and enhance image of radiologists but also ensure security of job of staff who have to work without contract in some of small radiology sets and imaging centers and also help in turf wars with nonradiologists and investors.

Hence, there is an urgent need to peruse quality program in radiology, lest there is danger of radiology as a specialty perishing. 